

Published in final edited form as:

Crit Care Clin. 2017 April ; 33(2): 245-258. doi:10.1016/j.ccc.2016.12.001.

\title{
Persistent Inflammation, Immunosuppression and Catabolism Syndrome (PICS)
}

\author{
A. Moore, MD \\ Department of Surgery and the Sepsis and Critical IIIness Research Center, University of Florida \\ College of Medicine, Gainesville, FL
}

Abstract

Over the past four decades the epidemiology of multiple organ failure (MOF) has evolved as a result of advances in care. A series of paradigms have been described to explain the pathophysiology of the new emerging predominant phenotypes. With the most recent improvements in the delivery of critical care, patients are less-frequently expiring early in their clinical course and in-hospital MOF-related mortality is on the decline. Unfortunately, this has resulted in a dramatic increase in the number of chronic critically ill patients (CCI) who linger in the intensive care unit (ICU), have high resource utilization, are discharged to non-home locations, experience sepsis recidivism requiring readmission, have persistent cognitive and functiona mpairments, and poor long-term survival. Within this population, we have proposed that a substantial subset of these patients suffer from a new phenotype termed Persistent Inflammation, Immunosuppression, and Catabolism Syndrome (PICS) which underlies these poor outcomes. While the mechanism(s) of PICS are under investigation, there is evidence that myelodysplasia ith expansion of myeloid derived suppressor cells, innate and adaptive immune suppression an protein catabolism with malnutrition are major contributors. Optimal care of these patients will support.

\footnotetext{
Correspondence should be directed to: Frederick A. Moore, MD. Professor and Chief of Acute Care Surgery, Department of Surgery, University of Florida College of Medicine, PO Box 100108, 1600 SW Archer Road, Gainesville, Florida 32610-0108, (352) 273 5670, FAX: (352) 273 5683, Frederick.Moore@ surgery.ufl.edu. Author contact information:

Juan C. Mira, MD., Post-Graduate Research Fellow, Department of Surgery, University of Florida College of Medicine, 1600 SW Archer Road, PO Box 100019, Gainesville, FL 32610-0019, juan.mira@ surgery.uf.edu

Scott C. Brakenridge MD, MSCS, FACS, Assistant Professor, Department of Surgery, University of Florida College of Medicine, PO Box 100108, 1600 SW Archer Road, Gainesville, Florida 32610-0108, Scott.Brakenridge@ surgery.ufl.

Lyle L. Moldawer, Ph.D., Professor, Department of Surgery, University of Florida College of Medicine, 1600 SW Archer Road Room 6116, PO Box 100286, Gainesville, Florida 32610-0286, moldawer@ surgery.ufl.edu

Publisher's Disclaimer: This is a PDF file of an unedited manuscript that has been accepted for publication. As a service to our customers we are providing this early version of the manuscript. The manuscript will undergo copyediting, typesetting, and review of the resulting proof before it is published in its final citable form. Please note that during the production process errors may be discovered which could affect the content, and all legal disclaimers that apply to the journal pertain.

Disclosure Statement: The authors have nothing to disclose.
} 


\section{Keywords}

Shock; Multiple Organ Failure; Trauma; Sepsis; Chronic Critical Illness; Cachexia; Myeloid Derived Suppressor Cells; PICS

\section{Introduction}

Multiple organ failure (MOF) has plagued surgical ICUs for over four decades and its epidemiology has evolved because advances in care have allowed patients to survive previously lethal insults. Over the years, different predominant phenotypes of MOF have been described; all have consumed tremendous healthcare resources and have been associated with prolonged ICU stays and prohibitive mortality. The term PICS has been coined to describe the most recent observed phenotype of persistent inflammation, immune suppression and protein catabolism which we believe represents the next challenge in surgical critical care. The purpose of this review is to describe the evolving epidemiology of MOF and the emergence of PICS, the PICS paradigm, the pathophysiology of PICS, and its clinical implications.

\section{Evolving Epidemiology of MOF and Emergence of PICS}

MOF emerged in the early 1970s as a result of advances in ICU technology that allowed patients to survive single organ failure (Figure 1$)^{1}$. Early studies provided convincing evidence that MOF occurred as a result of uncontrolled sepsis leading to fulminant organ failure and early death, with the primary source being intra-abdominal infections (IAI) ${ }^{1}$. As a result, research efforts in the early 1980's were focused on the prevention/treatment of IAI and were effective in reducing this highly fatal phenotypic expression of MOF. However, in the mid-1980s, studies out of Europe reported that MOF frequently occurred after severe blunt trauma with no identifiable site of infection ${ }^{2,3}$. The term "sepsis syndrome" was popularized to describe this phenomenon. It became widely accepted that MOF could ensue after both infectious and non-infectious insults by a similar auto-destructive systemic inflammatory response syndrome (SIRS). Research focus in the late 1980s shifted to determining the underlying mechanism(s) of "sepsis syndrome" (e.g. bacterial translocation, cytokine storm, ischemia reperfusion, etc.). Simultaneously with these research efforts, tremendous independent advances in trauma care occurred that substantially reduced early deaths from bleeding, but resulted in an epidemic of abdominal compartment syndrome (ACS) that emerged in the ICUs worldwide in the early $1990 \mathrm{~s}^{4}$. While clinical interest focused on understanding this as a new malignant MOF phenotype, epidemiology studies revealed that post-injury MOF was a bimodal phenomenon. Early MOF occurred after either an overwhelming insult ("one hit" model) or sequential amplifying insults ("two hit" model), while late MOF was precipitated by secondary nosocomial infections ${ }^{1}$.

The SIRS followed by a compensatory anti-inflammatory response syndrome (CARS) was originally proposed to describe the pathophysiology and bimodal distribution of MOF. SIRS-induced early MOF was believed to occur as a result of exaggerated innate immunity (principally mediated by neutrophils) while CARS set the stage for immunosuppressionassociated late infectious $\mathrm{MOF}^{5-8}$. The concept of CARS was initially based on trauma and 
sepsis studies that demonstrated that an early pro-inflammatory cytokine response was followed by an anti-inflammatory cytokine response, the purpose of which was believed to restore immunologic homeostasis. However, basic immunologists focused their research efforts on characterizing CARS and expanded its definition to include multiple defects in the adaptive immunity (principally related to lymphocytes) ${ }^{9-13}$. By the late 1990 s, fundamental changes in the initial care of patients arriving with severe bleeding were widely implemented [i.e. focused abdomen sonography of trauma (FAST), massive transfusion (MT) protocols, avoidance of excessive crystalloids and abandonment of pulmonary artery catheter (PAC) directed resuscitation] and the epidemic of ACS virtually disappeared ${ }^{14-17}$. Concordantly, evidence-based medicine (EBM) became a healthcare mandate and through the 2000s it was a major driver for improved ICU care.

Two initiatives had notable impacts on the epidemiology of MOF. The first was the NIH sponsored 'Glue Grant' which sought to characterize the genomic response to severe blunt trauma. To control the confounding effects of variable care, standard operating procedure (SOPs) for critical care were developed. Over the six year study period as a result of ongoing monitoring and improved SOP compliance, hospital mortality in the study cohort dropped from $22 \%$ to $11 \%{ }^{16}$. The second major initiative was the Surviving Sepsis Campaign. Its rationale was based on the recognition that a) the occurrence of severe sepsis in hospitalized patients was increasing, b) it was and continues to be the most expensive condition treated in US hospitals, c) its diagnosis was frequently delayed and d) severe sepsis directed SOPs were haphazardly delivered ${ }^{18-21}$. Implementation was an arduous process but hospital mortality of severe sepsis has decreased from above $35 \%$ to less than $15 \%{ }^{22-24}$. As a result of these initiatives and others, there has been another striking change in the epidemiology of MOF. Early in hospital mortality has decreased substantially and the incidence of late onset MOF deaths has largely disappeared. Unfortunately, a substantial portion of high risk MOF patients are surviving prolonged ICU stays and many are progressing into a new predominant MOF phenotype called PICS.

\section{The New Paradigm of PICS}

Based on recent laboratory and clinical research data, the following paradigm was proposed (Figure 2$)^{5}$. Following an inflammatory insult (either trauma or sepsis), SIRS and CARS occurs simultaneously. In some cases, SIRS can become overwhelming leading to an early MOF and fulminant death trajectory. Fortunately, modern ICU care is directed at early detection and prevention of this trajectory's fatal expression. If the severely insulted patients do not die of early MOF, there are two alternatives. Either their aberrant immunology rapidly recovers (i.e. achieves homeostasis) or its dysfunction persists and they enter chronic critical illness (CCI - defined as > 14 days in ICU with organ dysfunction). These CCI patients experience ongoing immunosuppression (e.g. lymphopenia) and inflammation (e.g. neutrophilia) that is associated with a persistent acute phase response (e.g. high CRPs) with ongoing somatic protein catabolism. Despite aggressive nutritional intervention, there is a tremendous loss of lean body mass and proportional decrease in functional status and poor wound healing. An estimated $30 \%$ to $50 \%$ of these CCI patients progress into PICS. Readily available clinical biomarkers may be used to identify patients with PICS (Table 1). Clinically, PICS patients suffer from recurrent nosocomial infections, poor wound healing 
and are often discharged to long-term acute care facilities (LTACs) where they experience sepsis recidivism requiring re-hospitalization, failure to rehabilitate and an indolent death ${ }^{5}$. As the population ages and perioperative care continues to improve, PICS will become the next challenging horizon in surgical critical care.

Dating back to the 1990s, there are reports describing CCI in ventilator-dependent patients. They primarily focused on describing the neuropathy and myopathy that caused significant long-term disability. More recently the CCI literature has emphasized that ICU delirium contributes to long-term cognitive impairments ${ }^{25}$. These reports largely come from heterogeneous medical ICU patients and variably implicate different risk factors including steroids, pharmacologic paralysis, immobilization, hyperglycemia and benzodiazepines. While these are likely operational in CCI related to PICS, the dominating risk factor for the PICS phenotype is recurrent inflammatory insults. This is not uncommon in the surgical ICU patient who is exposed to an initial major insult (e.g. surgery or trauma) and suffers recurrent inflammatory insults (operations, complications and nosocomial infections) that set up a state of persistent low grade inflammation, immunosuppression and protein catabolism. While not referred to as PICS, recent surgical literature documented improved early survival with poor long-term outcomes consistent with PICS after major burns ( $>30 \%$ BSA), major trauma (ISS $>15$ ), necrotizing pancreatitis and surgical sepsis ${ }^{26-30}$.

As part of our efforts to characterize PICS we have prospectively studied 147 trauma and surgical ICU patients over the past two years who experienced severe sepsis and septic shock (manuscript in preparation). A little over half were male, with a mean age of 60 years. These were sick patients (mean APACHE II $=23$ ), $70 \%$ had major comorbidities, $80 \%$ required emergency surgery, and 55\% presented in septic shock. Table 2 depicts biomarkers over 14 days consistent with PICS. Similarly, their clinical outcomes are consistent with PICS including low in-hospital mortality (13\%), high rate of nosocomial infection (52\%), few ventilator-free days (median 5, CI 1-11) and few ICU-free days (median 5,CI 0-5). Eighty-four (58\%) stayed ICU $\geq 14$ days and only 43 (29\%) were discharged to home.

\section{Pathophysiology of PICS}

While other investigators have described the growing epidemic of CCI, glaringly absent is any unifying mechanistic explanation. The PICS paradigm was described based on observed outcomes of surgical ICU patients who suffered a major inflammatory event (trauma/ surgical sepsis) and who experienced recurrent insults (principally nosocomial infections). We propose a mechanism that can explain the persistent low-grade inflammation with the concurrent adaptive immune suppression and associated ongoing catabolism after a devastating injury or infection.

In response to sepsis or trauma, bone marrow granulocytes demarginate from the bone marrow to the site of injury/infection creating space for hematopoietic stem cell (HSC) differentiation and repopulation of myeloid innate immune effector cells, a process termed "emergency myelopoiesis"31-34. Myeloid cell expansion predominates at the detriment of lymphopoiesis and erythropoiesis, promoting lymphopenia and anemia. Emergency myelopoiesis also results in the STAT3- and COX2- mediated expansion of a heterogeneous 
population of inducible immature myeloid cells with immunosuppressive properties termed myeloid-derived suppressor cells (MDSCs) ${ }^{35-38}$. The immunosuppressive activity to MDSCs has been attributed to a number of mechanisms and mediators described in both murine and human studies including the upregulation of arginase (ARG1) and nitric oxide synthase (NOS2), increased interleukin (IL)-10 production and cell surface expression of PD-L1 and CTLA4, nitrosylation of (major histocompatibility complex) MHC molecules preventing their appropriate interaction with the (T-cell receptor) TCR and coreceptors as well as promoting TCR dissociation, and promotion of regulatory T cell expansion ${ }^{35,39-45}$. While known for their adaptive immunosuppressive function, MDSCs also play an essential role in preserving innate immunity and producing inflammatory mediators such as NO, reactive oxygen species (ROS), tumor necrosis factor a (TNFa), regulated on activation normal T-cell expressed and secreted (RANTES) and macrophage inflammatory protein $1 \beta$ $(\mathrm{MIP}-1 \beta)^{46,47}$.

The emergency myelopoietic response and expansion of MDSCs in septic and trauma patients has been shown to be beneficial to the host by providing protection from early exuberant inflammation or from secondary infections ${ }^{33,39,48,49}$. Therefore, in addition to the contribution to systemic inflammation, emergency myelopoiesis is also important for early and late host protective immunity in the presence of suppressed adaptive immunity.

However, there is reason to believe that emergency myelopoiesis is impaired in the elderly, the population recognized to be at higher risk for CCI and PICS. Recently, Efron et al have shown that bone marrow progenitors in elderly mice fail to commence, and conclude with an appropriate myelopoietic response giving rise to myeloid cells with poor phagocytic and chemotactic function ${ }^{50}$. Additionally, in a subset of 72 of our above described severe sepsis and septic shock patients, we observed that MDSC expansion persists in the first 28 days post sepsis onset (Figure 3A) ${ }^{51}$. Additionally, the normally high monocytic/granulocytic ratio of MDSCs is reversed after severe sepsis and septic shock (Figure 3B and 3C). We also showed that these MDCSs suppressed T lymphocyte proliferation in vitro and suppressed the release of $\mathrm{T}_{\mathrm{H} 1}$ and $\mathrm{T}_{\mathrm{H} 2}$ cytokines. ${ }^{51}$. Finally, we showed early enhanced MDSC expansion was associated with early mortality (Figure 4), and that persistent expansion was associated with prolonged ICU stays. Multivariate analysis demonstrated that MDSC expansion was a strong independent predictor of nosocomial infections and poor post discharge disposition ${ }^{51}$. Thus, these data are supportive that prolonged expansion of MDSC after severe sepsis and septic shock contributes to outcomes consistent with the PICS phenotype.

In addition to MDSCs, sepsis and trauma patients suffer from significant tissue injury with release of damage-associated molecular patterns (DAMPs) ${ }^{52,53}$. These endogenous alarmins may also contribute to the persistent inflammation in PICS ${ }^{54,55}$ and their predominant sources are likely dysfunctional organs such as the kidneys and lungs as well as the intestine.

\section{Clinical Implications}

Persistent inflammation, MDSC expansion and suppression of protective immunity via anergy, lymphopenia, and dysfunctional innate effector cells predispose the patient to 
reactivation of latent viral infections, nosocomial infections, continued protein catabolism and malnutrition. This creates a propagating cycle were recurrent infections exacerbate inflammation driving aberrant myelopoiesis and continued expansion of MDSCs which turn induces suppression of adaptive immunity (Figure 5).

Treatment must focus on interrupting this viscous cycle facing the patient with CCI and PICS. Thus, treating PICS requires an understanding of the forces that drive the persistent inflammation, immunosuppression and catabolism that manifests in these patients.

Monotherapies will generally be ineffective unless they are pluripotent. Furthermore, most high risk patients bring with them a significant number of co-morbid diseases that all must be considered as part of the treatment plan.

Compliance with evidence-based management SOPs has significantly reduced in MOF deaths and continued compliance in survivors is important to limit iatrogenic injury and reduce sepsis recidivism ${ }^{16,56}$. Early enteral nutrition has been shown to reduce nosocomial infections. ${ }^{57}$,These diets should be supplemented with protein to insure $1.5 \mathrm{gm} / \mathrm{kg}$ and even more for burn patients and those requiring dialysis. While there is strong evidence supporting the use of immune-enhancing diets (IEDs) in trauma and perioperative patients, some have warned that the arginine in IEDs may cause harm in severe sepsis ${ }^{57}$. However, MDSCs expansion in survivors of severe sepsis promote immunosuppression via overexpression of arginase 1 which depletes arginine and thereby impairs lymphocyte proliferation. Thus, arginine supplementation may be important in preventing the survivors from progressing into CCI and PICS. For patients who have failed to wean off the ventilator, inspiratory strength training exercises have been showed to improve outcomes ${ }^{58}$.

Furthermore, other modes of physical therapy and mobilization, starting early in the ICU, have been shown to improve functional outcomes, decreased ICU and hospital stay, and improve quality of life ${ }^{59}$. Based on experience in severe burns, these patients will also likely benefit from receiving anabolic hormones, intensive insulin therapy and beta-blockade ${ }^{60}$.

Despite failed attempts at pharmacological intervention in trauma and sepsis, there is optimism on future drug development for the interruption of this cycle ${ }^{61}$. Most antiinflammatory modulations has been attempted early after the initial septic/trauma event but not during the continuing smoldering inflammation seen in PICS. Additionally, similarities in immune suppression seen in CCI and advanced cancer provide a rational for the implementation of immune system stimulants in these patients ${ }^{62,63}$. In the settings of advanced cancer, blockade of checkpoint inhibitors, such as CTLA4 and PD-L1, either alone, in combination, or with methyltransferase inhibitors have demonstrated improvements in adaptive immunity and durable response rates ${ }^{64,65}$. Clinical trials with anti-PD-L1 in sepsis are currently underway [NCT:02576457].

\section{Conclusion}

Management of MOF has evolved significantly over the past four decades as has our understanding of the pathobiology of trauma and sepsis. Advances in the early management and resuscitation of trauma and sepsis have significant reduced early mortality and early MOF. Additionally, there has been a significant reduction in late stage MOF and steady 
improvements in hospital survival for both entities. This successful recognition and management of the early inflammatory response has resulted in increased numbers of patients who reside in critical care units with persistent inflammation, adaptive immune suppression, defects in antigen presentation, protein catabolism, somatic tissue wasting and dismal long-term outcomes. We provide a new terminology for this patient population, PICS, that recognizes the principle challenges to the successful management of these patients: management of their chronic inflammatory state, restoration of a more appropriate adaptive immune response and protection against secondary nosocomial infections, as well as prevention or restoration of a cachectic, wasting syndrome. Furthermore, it recognizes that such patients have multiple, simultaneous immunological and physiological defects that require a multi-modal therapeutic approach instead of single monotherapy treatment.

We believe that MDSCs may play a significant role in the in the persistent inflammation, and immunosuppression, leading to detrimental long-term outcomes following severe trauma and sepsis. Furthermore, identifying MDSCs in humans, as well as understanding their biological and immunological contributions to the host during sepsis and trauma may not only offer a mechanism of this disease but also possible therapeutic targets to improve clinical outcomes. The PICS model argues that immunoadjuvants such as antiPD-L1 or IL-7, or drugs that can suppress the expansion of MDSCs, may benefit this population by reducing the likelihood of opportunistic infections or viral reactivation. In addition to supportive therapies aimed at reducing the likelihood of nosocomial infection, stimulation of anabolic signals with the implementation of early patient mobilization, resistance exercise, and optimization of nutritional support are suggested. Ultimately, it is a combination of pharmacotherapy, physiotherapy and nutritional support that will most likely benefit these patients.

\section{Acknowledgments}

Supported in part by grants P50 GM-111152-03, R01 GM-40586-24 and R01 GM-104481-04, awarded by the National Institute of General Medical Sciences (NIGMS), U.S.P.H.S. JCM was supported by a postgraduate training grant (T32 GM-08721) in burns, trauma and perioperative injury by NIGMS.

\section{References}

1. Moore FA, Moore EE. Evolving concepts in the pathogenesis of postinjury multiple organ failure. The Surgical clinics of North America. Apr; 1995 75(2):257-277. [PubMed: 7899997]

2. Waydhas C, Nast-Kolb D, Jochum M, et al. Inflammatory mediators, infection, sepsis, and multiple organ failure after severe trauma. Archives of surgery. Apr; 1992 127(4):460-467. [PubMed: 1348412]

3. Faist E, Baue AE, Dittmer H, Heberer G. Multiple organ failure in polytrauma patients. The Journal of trauma. Sep; 1983 23(9):775-787. [PubMed: 6620431]

4. Balogh Z, McKinley BA, Cox CS Jr, et al. Abdominal compartment syndrome: the cause or effect of postinjury multiple organ failure. Shock. Dec; 2003 20(6):483-492. [PubMed: 14625470]

5. Gentile LF, Cuenca AG, Efron PA, et al. Persistent inflammation and immunosuppression: A common syndrome and new horizon for surgical intensive care. The journal of trauma and acute care surgery. Jun; 2012 72(6):1491-1501. [PubMed: 22695412]

6. Ward NS, Casserly B, Ayala A. The compensatory anti-inflammatory response syndrome (CARS) in critically ill patients. Clinics in chest medicine. Dec; 2008 29(4):617-625, viii. [PubMed: 18954697] 
7. Rosenthal MD, Moore FA. Persistent inflammatory, immunosuppressed, catabolic syndrome (PICS): A new phenotype of multiple organ failure. Journal of advanced nutritional and human metabolism. Apr 26.2015 1(1)

8. Robertson CM, Coopersmith CM. The systemic inflammatory response syndrome. Microbes and infection/Institut Pasteur. Apr; 2006 8(5):1382-1389.

9. Moldawer LL. Interleukin-1, TNF alpha and their naturally occurring antagonists in sepsis. Blood purification. 1993; 11(2):128-133. [PubMed: 8274244]

10. Rogy MA, Coyle SM, Oldenburg HS, et al. Persistently elevated soluble tumor necrosis factor receptor and interleukin-1 receptor antagonist levels in critically ill patients. J Am Coll Surg. Feb; 1994 178(2):132-138. [PubMed: 8173722]

11. Rogy MA, Oldenburg HS, Coyle S, Trousdale R, Moldawer LL, Lowry SF. Correlation between Acute Physiology and Chronic Health Evaluation (APACHE) III score and immunological parameters in critically ill patients with sepsis. The British journal of surgery. Mar; 1996 83(3): 396-400. [PubMed: 8665205]

12. MacLean LD, Meakins JL, Taguchi K, Duignan JP, Dhillon KS, Gordon J. Host resistance in sepsis and trauma. Annals of surgery. Sep; 1975 182(3):207-217. [PubMed: 126046]

13. Bone RC. Toward a theory regarding the pathogenesis of the systemic inflammatory response syndrome: what we do and do not know about cytokine regulation. Crit Care Med. Jan; 1996 24(1):163-172. [PubMed: 8565523]

14. Sauaia A, Moore EE, Johnson JL, et al. Temporal trends of postinjury multiple-organ failure: still resource intensive, morbid, and lethal. The journal of trauma and acute care surgery. Mar; 2014 76(3):582-592. discussion 592-583. [PubMed: 24553523]

15. Gonzalez EA, Moore FA. Resuscitation beyond the abdominal compartment syndrome. Current opinion in critical care. Dec; 2010 16(6):570-574. [PubMed: 23361130]

16. Cuschieri J, Johnson JL, Sperry J, et al. Benchmarking outcomes in the critically injured trauma patient and the effect of implementing standard operating procedures. Annals of surgery. May; 2012 255(5):993-999. [PubMed: 22470077]

17. Sobrino J, Shafi S. Timing and causes of death after injuries. Proceedings. Apr; 2013 26(2):120 123.

18. Torio, CM., Andrews, RM. Healthcare Cost and Utilization Project (HCUP) Statistical Briefs. Rockville (MD): 2013. National Inpatient Hospital Costs: The Most Expensive Conditions by Payer, 2011: Statistical Brief \#160.

19. Gaieski DF, Edwards JM, Kallan MJ, Carr BG. Benchmarking the incidence and mortality of severe sepsis in the United States. Crit Care Med. May; 2013 41(5):1167-1174. [PubMed: 23442987]

20. Dellinger RP, Carlet JM, Masur H, et al. Surviving Sepsis Campaign guidelines for management of severe sepsis and septic shock. Intensive care medicine. Apr; 2004 30(4):536-555. [PubMed: 14997291]

21. Dellinger RP, Levy MM, Rhodes A, et al. Surviving sepsis campaign: international guidelines for management of severe sepsis and septic shock: 2012. Crit Care Med. Feb; 2013 41(2):580-637. [PubMed: 23353941]

22. Rhodes A, Phillips G, Beale R, et al. The Surviving Sepsis Campaign bundles and outcome: results from the International Multicentre Prevalence Study on Sepsis (the IMPreSS study). Intensive care medicine. Sep; 2015 41(9):1620-1628. [PubMed: 26109396]

23. Gao F, Melody T, Daniels DF, Giles S, Fox S. The impact of compliance with 6-hour and 24-hour sepsis bundles on hospital mortality in patients with severe sepsis: a prospective observational study. Critical care. 2005; 9(6):R764-770. [PubMed: 16356225]

24. Castellanos-Ortega A, Suberviola B, Garcia-Astudillo LA, et al. Impact of the Surviving Sepsis Campaign protocols on hospital length of stay and mortality in septic shock patients: results of a three-year follow-up quasi-experimental study. Crit Care Med. Apr; 2010 38(4):1036-1043. [PubMed: 20154597]

25. Pandharipande PP, Girard TD, Jackson JC, et al. Long-term cognitive impairment after critical illness. The New England journal of medicine. Oct 3; 2013 369(14):1306-1316. [PubMed: 24088092] 
26. Davidson GH, Hamlat CA, Rivara FP, Koepsell TD, Jurkovich GJ, Arbabi S. Long-term survival of adult trauma patients. Jama. Mar 9; 2011 305(10):1001-1007. [PubMed: 21386078]

27. Callcut RA, Wakam G, Conroy AS, et al. Discovering the truth about life after discharge: Longterm trauma-related mortality. The journal of trauma and acute care surgery. Feb; 2016 80(2):210 217. [PubMed: 26606176]

28. Skouras C, Hayes AJ, Williams L, Garden OJ, Parks RW, Mole DJ. Early organ dysfunction affects long-term survival in acute pancreatitis patients. HPB : the official journal of the International Hepato Pancreato Biliary Association. Sep; 2014 16(9):789-796. [PubMed: 24712663]

29. Timmers TK, Verhofstad MH, Moons KG, Leenen LP. Long-term survival after surgical intensive care unit admission: fifty percent die within 10 years. Annals of surgery. Jan; 2011 253(1):151157. [PubMed: 21135693]

30. Pavoni V, Gianesello L, Paparella L, Buoninsegni LT, Barboni E. Outcome predictors and quality of life of severe burn patients admitted to intensive care unit. Scandinavian journal of trauma, resuscitation and emergency medicine. 2010; 18:24.

31. Manz MG, Boettcher S. Emergency granulopoiesis. Nat Rev Immunol. May; 2014 14(5):302-314. [PubMed: 24751955]

32. Furze RC, Rankin SM. Neutrophil mobilization and clearance in the bone marrow. Immunology. Nov; 2008 125(3):281-288. [PubMed: 19128361]

33. Scumpia PO, Kelly-Scumpia KM, Delano MJ, et al. Cutting edge: bacterial infection induces hematopoietic stem and progenitor cell expansion in the absence of TLR signaling. J Immunol. Mar 1; 2010 184(5):2247-2251. [PubMed: 20130216]

34. Ueda Y, Kondo M, Kelsoe G. Inflammation and the reciprocal production of granulocytes and lymphocytes in bone marrow. The Journal of experimental medicine. Jun 6; 2005 201(11):17711780. [PubMed: 15939792]

35. Gabrilovich DI, Nagaraj S. Myeloid-derived suppressor cells as regulators of the immune system. Nat Rev Immunol. Mar; 2009 9(3):162-174. [PubMed: 19197294]

36. Dilek N, Vuillefroy de Silly R, Blancho G, Vanhove B. Myeloid-derived suppressor cells: mechanisms of action and recent advances in their role in transplant tolerance. Front Immunol. 2012; 3:208. [PubMed: 22822406]

37. Bronte V. Myeloid-derived suppressor cells in inflammation: uncovering cell subsets with enhanced immunosuppressive functions. European journal of immunology. Oct; 2009 39(10): 2670-2672. [PubMed: 19757440]

38. Talmadge JE, Gabrilovich DI. History of myeloid-derived suppressor cells. Nature reviews. Cancer. Oct; 2013 13(10):739-752. [PubMed: 24060865]

39. Cuenca AG, Delano MJ, Kelly-Scumpia KM, et al. A paradoxical role for myeloid-derived suppressor cells in sepsis and trauma. Molecular medicine. Mar-Apr;2011 17(3-4):281-292. [PubMed: 21085745]

40. Popovic PJ, Zeh HJ 3rd, Ochoa JB. Arginine and immunity. J Nutr. Jun; 2007 137(6 Suppl 2): 1681S-1686S. [PubMed: 17513447]

41. Heim CE, Vidlak D, Kielian T. Interleukin-10 production by myeloid-derived suppressor cells contributes to bacterial persistence during Staphylococcus aureus orthopedic biofilm infection. J Leukoc Biol. Dec; 2015 98(6):1003-1013. [PubMed: 26232453]

42. Lei GS, Zhang C, Lee CH. Myeloid-derived suppressor cells impair alveolar macrophages through PD-1 receptor ligation during Pneumocystis pneumonia. Infection and immunity. Feb; 2015 83(2): 572-582. [PubMed: 25404033]

43. Bunt SK, Sinha P, Clements VK, Leips J, Ostrand-Rosenberg S. Inflammation induces myeloidderived suppressor cells that facilitate tumor progression. J Immunol. Jan 1; 2006 176(1):284-290. [PubMed: 16365420]

44. Nagaraj S, Gupta K, Pisarev V, et al. Altered recognition of antigen is a mechanism of CD8+ T cell tolerance in cancer. Nat Med. Jul; 2007 13(7):828-835. [PubMed: 17603493]

45. Youn JI, Nagaraj S, Collazo M, Gabrilovich DI. Subsets of myeloid-derived suppressor cells in tumor-bearing mice. J Immunol. Oct 15; 2008 181(8):5791-5802. [PubMed: 18832739] 
46. Delano MJ, Scumpia PO, Weinstein JS, et al. MyD88-dependent expansion of an immature GR-1(+)CD11b(+) population induces $\mathrm{T}$ cell suppression and Th2 polarization in sepsis. The Journal of experimental medicine. Jun 11; 2007 204(6):1463-1474. [PubMed: 17548519]

47. Noel JG, Osterburg A, Wang Q, et al. Thermal injury elevates the inflammatory monocyte subpopulation in multiple compartments. Shock. Dec; 2007 28(6):684-693. [PubMed: 17607156]

48. Noel G, Wang Q, Osterburg A, et al. A ribonucleotide reductase inhibitor reverses burn-induced inflammatory defects. Shock. Nov; 2010 34(5):535-544. [PubMed: 20386495]

49. Sander LE, Sackett SD, Dierssen U, et al. Hepatic acute-phase proteins control innate immune responses during infection by promoting myeloid-derived suppressor cell function. The Journal of experimental medicine. Jul 5; 2010 207(7):1453-1464. [PubMed: 20530204]

50. Nacionales DC, Szpila B, Ungaro R, et al. A Detailed Characterization of the Dysfunctional Immunity and Abnormal Myelopoiesis Induced by Severe Shock and Trauma in the Aged. J Immunol. Sep 1; 2015 195(5):2396-2407. [PubMed: 26246141]

51. Mathias B, Delmas AL, Ozrazgat-Baslanti T, et al. Human Myeloid-derived Suppressor Cells are Associated With Chronic Immune Suppression After Severe Sepsis/Septic Shock. Annals of surgery. May 9.2016

52. Yamanouchi S, Kudo D, Yamada M, Miyagawa N, Furukawa H, Kushimoto S. Plasma mitochondrial DNA levels in patients with trauma and severe sepsis: time course and the association with clinical status. J Crit Care. Dec; 2013 28(6):1027-1031. [PubMed: 23787023]

53. Gao S, Yang Y, Fu Y, Guo W, Liu G. Diagnostic and prognostic value of myeloid-related protein complex 8/14 for sepsis. The American journal of emergency medicine. Sep; 2015 33(9):12781282. [PubMed: 26206243]

54. Kang JW, Kim SJ, Cho HI, Lee SM. DAMPs activating innate immune responses in sepsis. Ageing research reviews. Nov; 2015 24(Pt A):54-65. [PubMed: 25816752]

55. Timmermans K, Kox M, Scheffer GJ, Pickkers P. Danger in the Intensive Care Unit: Damps in Critically Ill Patients. Shock. Feb; 2016 45(2):108-116. [PubMed: 26513703]

56. Levy MM, Rhodes A, Phillips GS, et al. Surviving Sepsis Campaign: association between performance metrics and outcomes in a 7.5-year study. Crit Care Med. Jan; 2015 43(1):3-12. [PubMed: 25275252]

57. McClave SA, Taylor BE, Martindale RG, et al. Guidelines for the Provision and Assessment of Nutrition Support Therapy in the Adult Critically Ill Patient: Society of Critical Care Medicine (SCCM) and American Society for Parenteral and Enteral Nutrition (A.S.P.E.N.). JPEN. Journal of parenteral and enteral nutrition. Feb; 2016 40(2):159-211. [PubMed: 26773077]

58. Martin AD, Smith BK, Davenport PD, et al. Inspiratory muscle strength training improves weaning outcome in failure to wean patients: a randomized trial. Critical care. 2011; 15(2):R84. [PubMed: 21385346]

59. Kayambu G, Boots R, Paratz J. Physical therapy for the critically ill in the ICU: a systematic review and meta-analysis. Crit Care Med. Jun; 2013 41(6):1543-1554. [PubMed: 23528802]

60. Jeschke MG, Chinkes DL, Finnerty CC, et al. Pathophysiologic response to severe burn injury. Annals of surgery. Sep; 2008 248(3):387-401. [PubMed: 18791359]

61. Fink MP, Warren HS. Strategies to improve drug development for sepsis. Nature reviews. Drug discovery. Oct; 2014 13(10):741-758. [PubMed: 25190187]

62. Hotchkiss RS, Opal S. Immunotherapy for sepsis-a new approach against an ancient foe. The New England journal of medicine. Jul 1; 2010 363(1):87-89. [PubMed: 20592301]

63. Hotchkiss RS, Moldawer LL. Parallels between cancer and infectious disease. The New England journal of medicine. Jul 24; 2014 371(4):380-383. [PubMed: 25054723]

64. Ott PA, Hodi FS, Robert C. CTLA-4 and PD-1/PD-L1 blockade: new immunotherapeutic modalities with durable clinical benefit in melanoma patients. Clinical cancer research :an official journal of the American Association for Cancer Research. Oct 1; 2013 19(19):5300-5309. [PubMed: 24089443]

65. Redman JM, Gibney GT, Atkins MB. Advances in immunotherapy for melanoma. BMC medicine. 2016; 14(1):20. [PubMed: 26850630] 


\section{Synopsis}

Following advances in critical care, in-hospital MOF-related mortality is declining. Consequently, incidence of chronic critical illness is rising. These patients linger in the intensive care unit, have high resource utilization, and poor long-term outcomes. Within this population, we propose that a substantial subset of patients suffer from a new phenotype: Persistent Inflammation, Immunosuppression, and Catabolism Syndrome (PICS). While the mechanism(s) of PICS are under investigation, there is evidence that myelodysplasia with expansion of myeloid derived suppressor cells, innate and adaptive immune suppression and protein catabolism with malnutrition are major contributors. Optimal care of these patients will require novel multimodality interventions. 


\section{Key Points}

1. There has been a significant rise in patients with chronic critical illness (CCI); patients with prolonged hospitalizations, high resource utilization and dismal long-term outcomes.

2. Persistent Inflammation, Immunosuppression, and Catabolism Syndrome (PICS) describes a subgroup of patients with CCI who have experienced recurrent inflammatory insults.

3. Prolonged expansion of myeloid derived suppressor cells (MDSCs) provides a plausible mechanism for the pathobiology and poor outcomes observed in patients with PICS.

4. MDSC expansion in emergency myelopoiesis can lead to chronic inflammation, suppression of adaptive immunity and predisposes the patient to nosocomial infections.

5. A combination of pharmacotherapy, physiotherapy and nutritional support will be necessary to limit the progression of CCI into PICS. 


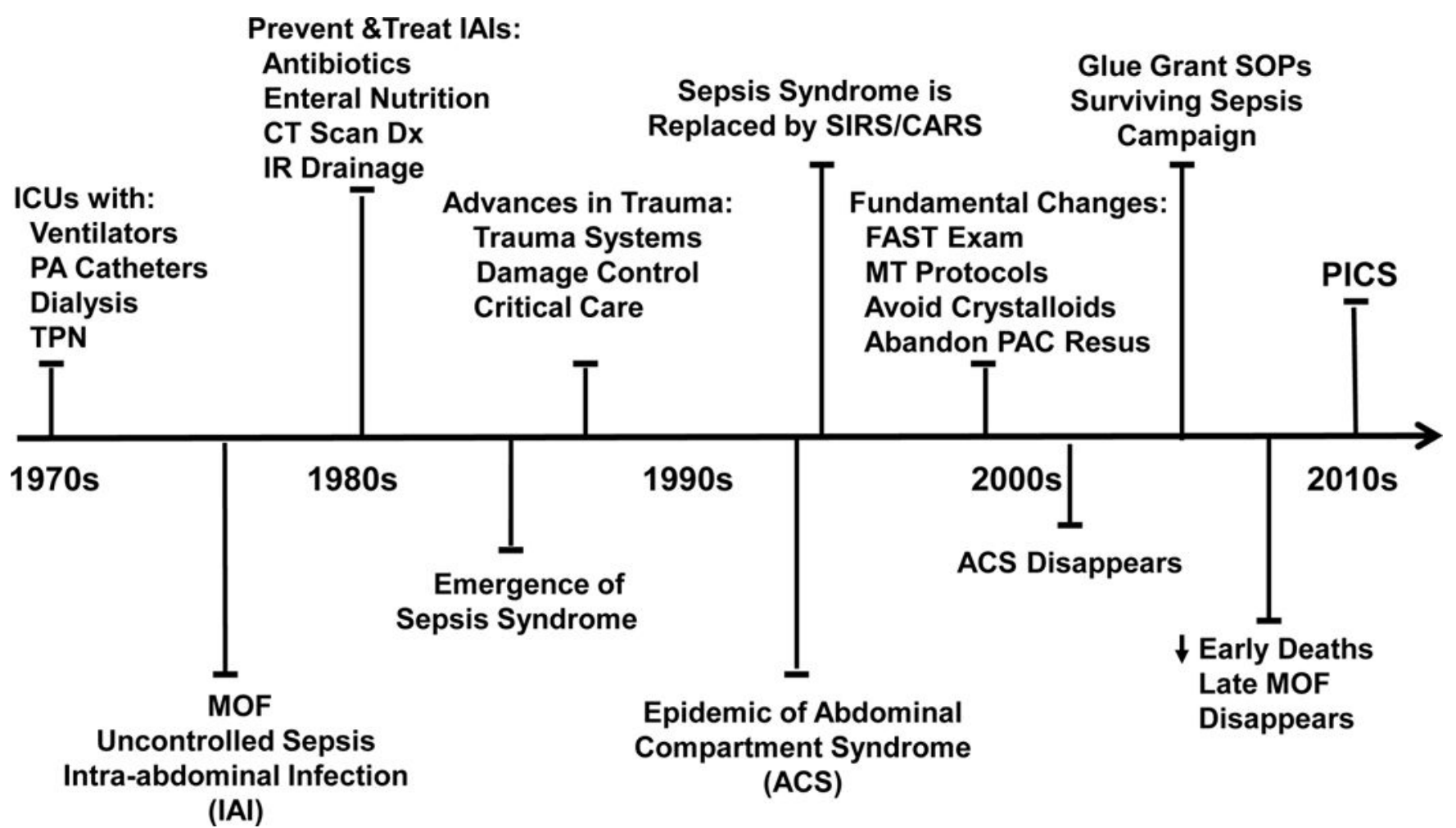

Figure 1. Evolution of MOF

MOF evolves over 40 years as does the clinical and surgical management of shock states.

Paradigms to explain the developing phenotypes are adopted and discarded. We propose that PICS is the predominant phenotype resulting from CCI. 


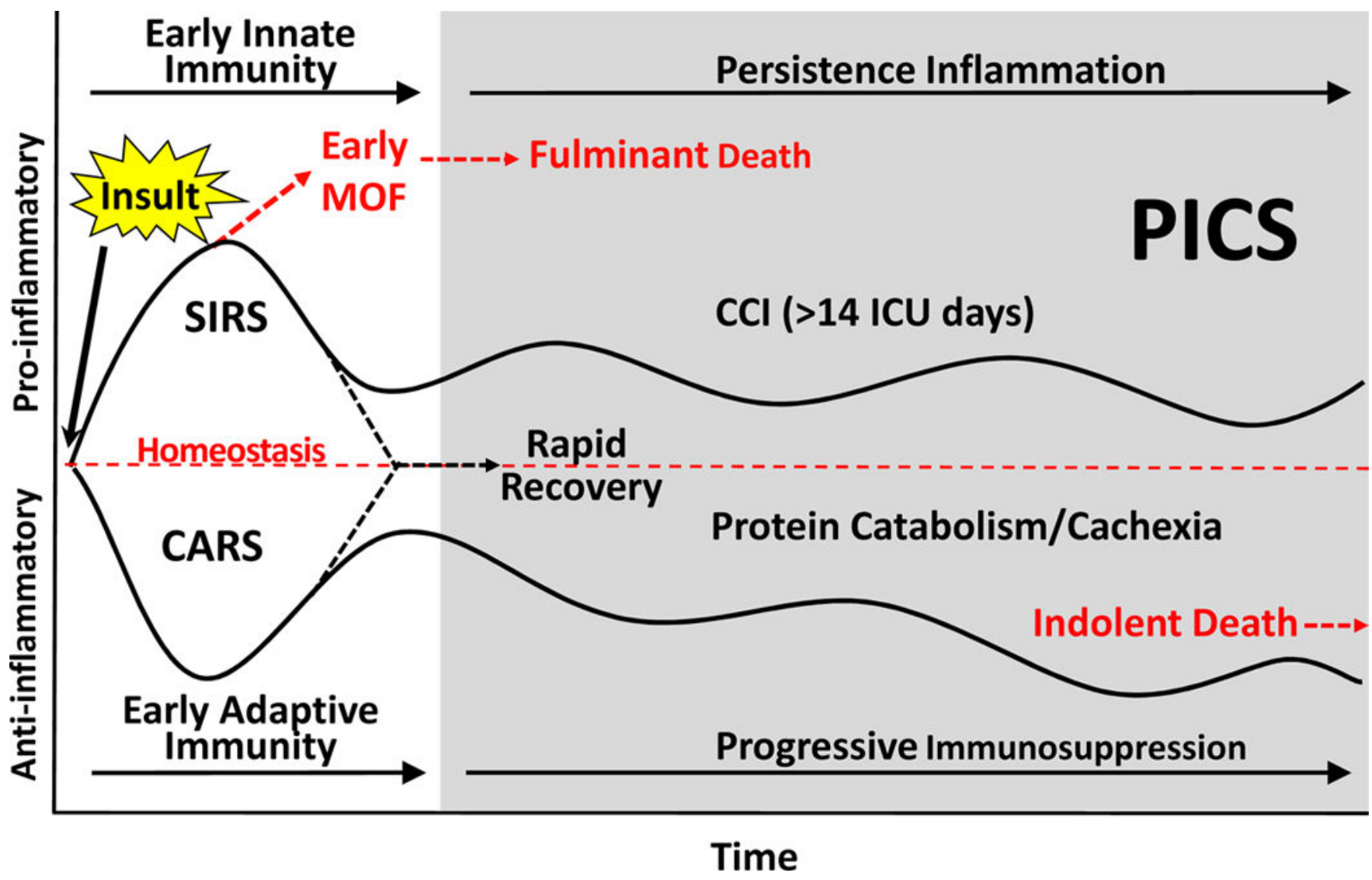

Figure 2. PICS paradigm

Following a major inflammatory insult (trauma, sepsis, burns, acute pancreatitis, etc) there is a simultaneous inflammatory and immunosuppressive response. Early deaths from acute MOF are now rare due to early recognition of shock and rapid implementation of supportive care thorough effective application of EBM and SOPs. Survivors may progress through two pathways: 1) patients readily return to immune homeostasis and achieve a rapid recovery; 2) patients smolder in the ICU with CCI and develop chronic inflammation, suppression of adaptive immunity, ongoing protein catabolism with cachectic wasting, and suffer from recurrent nosocomial infections. These patients often suffer from PICS, many of which fail to achieve functional independence, are discharged to LTACs, have and extremely poor quality of life, and ultimately succumb to an indolent death.

Adapted from Gentile LF, Cuenca AG, Efron PA, et al. Persistent inflammation and immunosuppression: A common syndrome and new horizon for surgical intensive care. The journal of trauma and acute care surgery. Jun 2012 72(6):1491-1501.

Abbreviations: MOF - multiple organ failure; SIRS - systemic inflammatory response syndrome; CARS - compensatory anti-inflammatory response syndrome; CCI - Chronic Critical Illness; ICU - Intensive Care Unit; PICS - persistent immune suppression inflammation and catabolism syndrome; 
A.

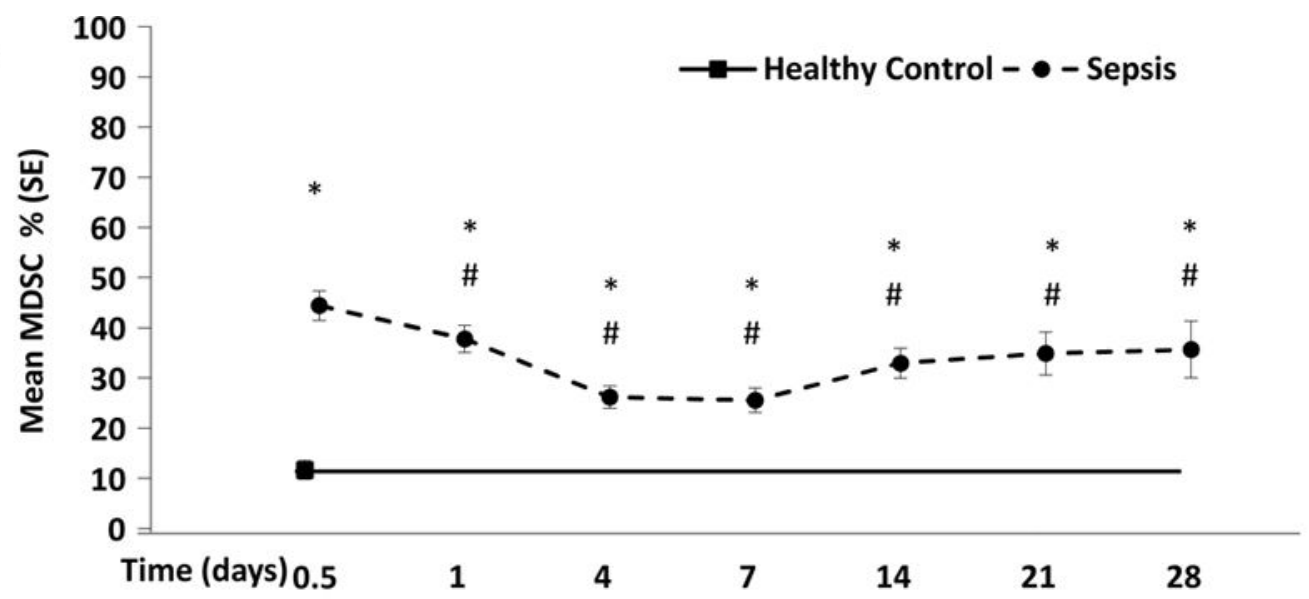

B.

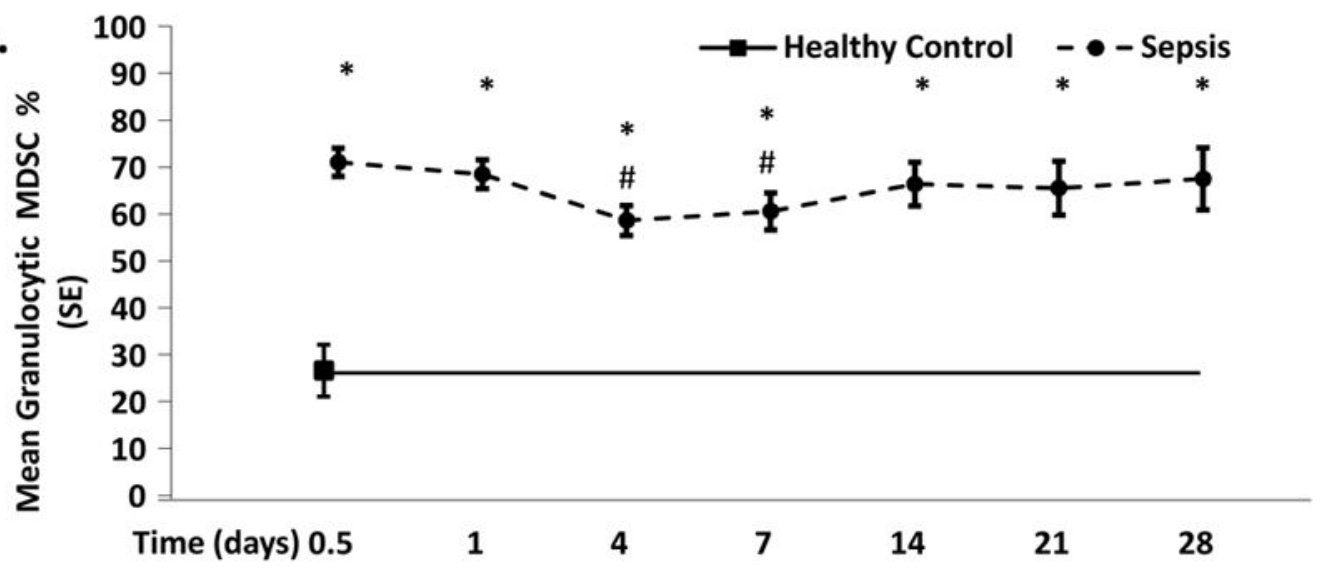

C.

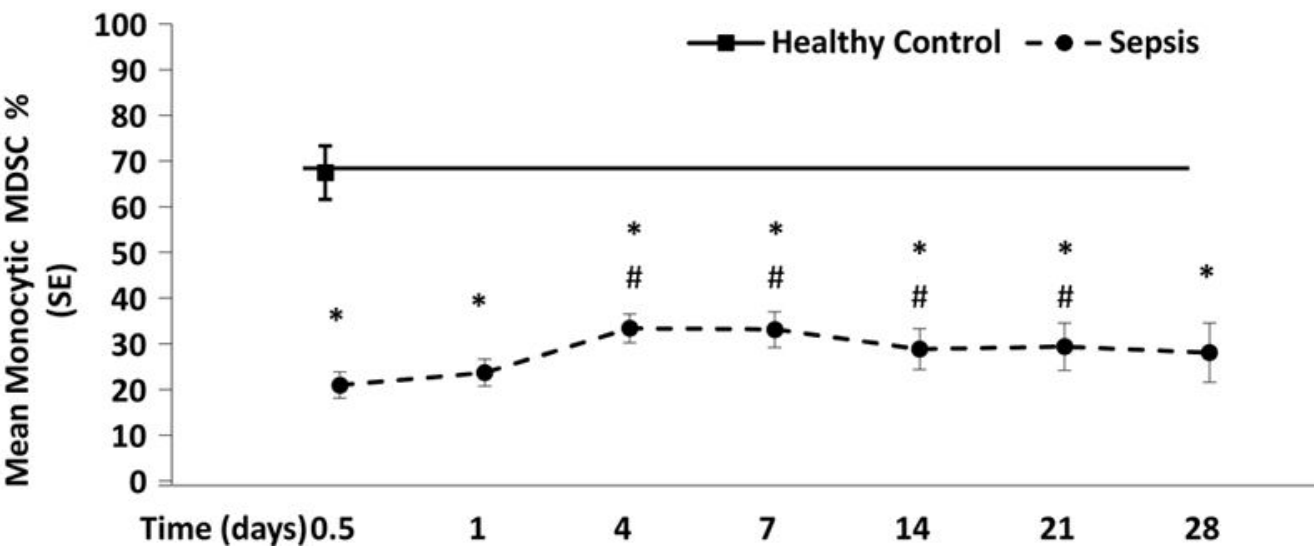

Figure 3. MDSCs in PICS

Characterization of MDSCs $\left(\mathrm{CD}_{3} 3^{+} \mathrm{CD} 11 \mathrm{~b}^{+} \mathrm{HLA}^{-} \mathrm{DR}^{-/ \text {low }}\right)$ in 72 trauma and surgical ICU patients with severe sepsis/septic shock ${ }^{51}$. A) After sepsis onset, circulating MDSCs expand early and are persistently elevated by a significant margin over the first 28 days when compared to healthy controls. B \& C) The commonly observed high ratio of monocytic/ granulocytic MDSCs seen in healthy subjects is reversed in patients with severe sepsis/septic shock. 
From Mathias B, Delmas AL, Ozrazgat-Baslanti T, et al. Human Myeloid-derived Suppressor Cells are Associated With Chronic Immune Suppression After Severe Sepsis/ Septic Shock. Annals of surgery. May 92016

* $\mathrm{p}<0.05$ when compared to HC subjects

\# $\mathrm{p}<0.05$ when compared to SS/SS patients at 12 hours. 


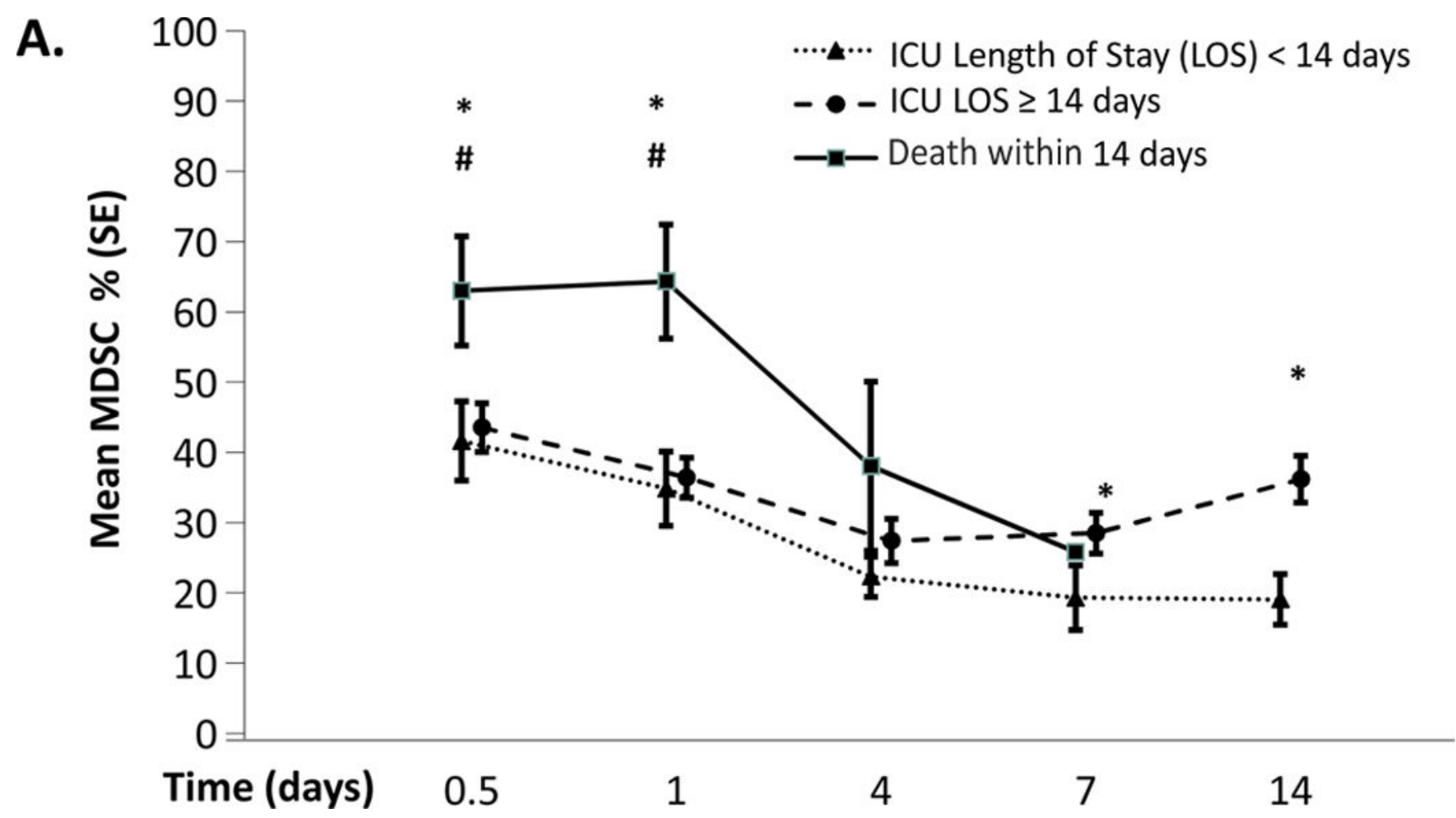

Figure 4. MDSCs and ICU mortality/length of stay

Increase in circulating MDSCs correlates with early mortality and prolonged length of stay. MDSC expansion was more significant in patients with early mortality ( $<14$ days) than in patients who survived $>14$ days at both 12 hours and 24 hours after sepsis onset. MDSC levels then decline until death. In patients with a prolonged ICU stay (>14days), MDSCs are significantly elevated at 7 days and 14days when compared to patients with and ICU length of stay of $<14$ days.

From Mathias B, Delmas AL, Ozrazgat-Baslanti T, et al. Human Myeloid-derived Suppressor Cells are Associated With Chronic Immune Suppression After Severe Sepsis/ Septic Shock. Annals of surgery. May 92016 * $\mathrm{p}<0.05$ when compared to patients with ICU LOS $<14$ days $\# \mathrm{p}<0.05$ when compared to patients with ICU LOS $\geq 14$ days 


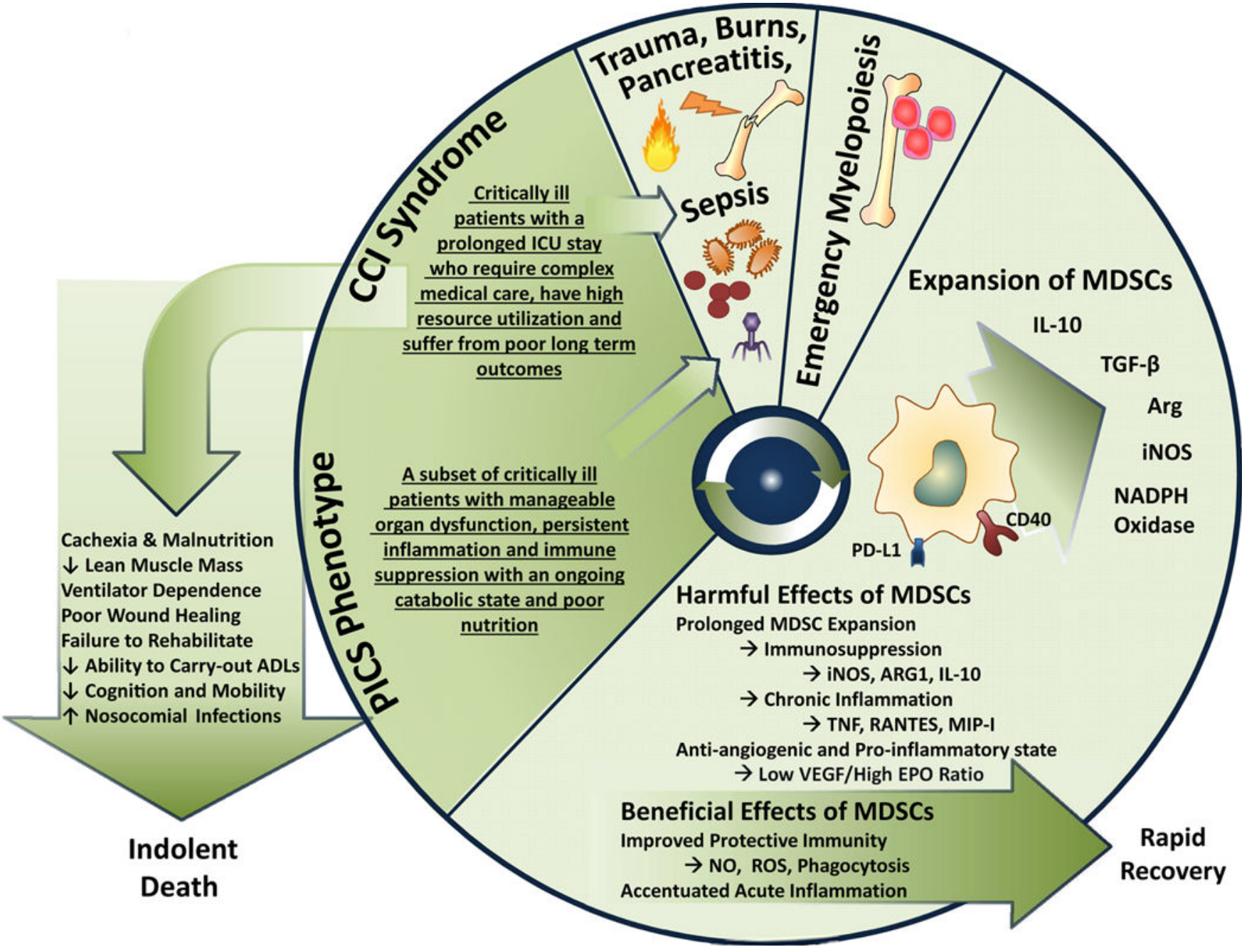

Figure 5. The PICS cycle

PICS can be represented as a recurring, vicious cycle. First, the inciting inflammatory event stimulates an emergency myelopoietic response. While the ensuing expansion of MDSC can be protective, prolonged expansion promotes suppression of adaptive immunity and chronic inflammation. Following this initial response, the patient may convalesce or progress to CCI. In a subset of CCI patients PICS develops and is characterized by manageable organ dysfunction, ongoing inflammation and immune suppression, protein catabolism, muscle wasting, and unmet nutritional needs. This predisposes the patient for recurrent infections and recidivism of this cycle.

Modified from Mira et al (in press). 


\section{Table 1}

\section{PICS biomarkers}

Laboratory markers that are readily available in most clinical settings and can be used to identify patients with or at risk of PICS.

\begin{tabular}{ll}
\hline PICS & Measurement \\
\hline Critically ill patient & Admission to the ICU $>14$ days \\
\hline Persistent inflammation & CRP $>50 \mu \mathrm{g} / \mathrm{dL}$ \\
\hline Persistent immunosuppression & Total lymphocyte count $<0.80 \times 10^{9} / \mathrm{L}$ \\
\hline Catabolic state & Serum albumin $<3.0 \mathrm{~g} / \mathrm{dL}$ \\
& $\begin{array}{l}\text { Pre-albumin }<10 \mathrm{mg} / \mathrm{dL} \\
\text { Creatinine height index }<80 \% \\
\\
\text { Weight loss }>10 \% \text { 'or' BMI }<18 \text { during hospitalization }\end{array}$ \\
\hline
\end{tabular}

Abbreviations: PICS - Persistent Inflammation, Immunosuppression and Catabolism Syndrome; ICU - Intensive Care Unit; CRP - C-reactive protein; BMI - Body mass index; 


\section{Table 2}

\section{PICS biomarkers over time}

Clinical biomarkers of PICS at three time points in chronically ill patients with severe sepsis/septic shock: sepsis onset, day 7 and day 14. These are consistent with the persistent inflammation, immune suppression, and catabolism seen in patients with PICS.

\begin{tabular}{llccc}
\hline PICS & Marker & Sepsis Onset & Day 7 & Day 14 \\
\hline Inflammation & & & & \\
\hline & CRP $(\mathbf{m g} / \mathbf{L})$ & $206 \pm 25$ & $118 \pm 58$ & $86 \pm 75$ \\
\hline & Neutrophils $\left(\mathbf{K} / \mathbf{m m}^{\mathbf{3}}\right)$ & $15 \pm 3$ & $12 \pm 6$ & $10 \pm 7$ \\
\hline Immunosuppression & & & \\
\hline & Lymphocytes $\left(\mathbf{K} / \mathbf{m m}^{3}\right)$ & $0.6 \pm 0.4$ & $1.1 \pm 1.3$ & $1.0 \pm 0.8$ \\
\hline Catabolism & & & \\
\hline \multicolumn{5}{c}{ Albumin $(\mathbf{g m} / \mathbf{d l})$} \\
\hline & Pre-Albumin $(\mathbf{m g} / \mathbf{L})$ & $6 \pm 2$ & $7 \pm 3$ & $10 \pm 5$ \\
\hline
\end{tabular}

